\title{
Mathability and Creative Problem Solving in the MaTech Math Competition
}

\author{
Attila Kovari ${ }^{1}$, Monika Rajcsanyi-Molnar ${ }^{2}$ \\ ${ }^{1}$ Institute of Engineering, University of Dunaujvaros, Tancsics M. ut 1/A, 2400, \\ Dunaujvaros, Hungary, kovari@uniduna.hu \\ ${ }^{2}$ Institute of Social Sciences, University of Dunaujvaros, Tancsics M. ut 1/A, \\ 2400, Dunaujvaros, Hungary, molnarmo@uniduna.hu
}

Abstract: The Klebelsberg Center and the University of Dunaújváros, as a professional partner, organized the national MaTech math competition for the second time in 2019. The main goal of this competition is to develop creativity, creative problem solving, teamwork, and apply of digital knowledge in real mathematical problems when the mathematical capabilities co-evolving with human-ICT systems. This work presents an analysis identifying the characteristics of the mathematical knowledge and the relationship with the skill of creative presentation and performance.

Keywords: digital knowledge; creativity; teamwork; knowledge management

\section{Introduction}

For the second time in 2019, Klebelsberg Centre and the University of Dunaújváros, as a professional partner, organized the national MaTech math competition [1]. The competition is extraordinary in several aspects. First, participants have to cooperate in teamwork; the competition is conducted with the participation of groups of 3 members. Second, the use of digital tools is not prohibited; moreover, their professional use, in order to quickly solve the tasks, is inevitable. Third, such tasks need to be solved by the students in the competition, where a presentation accompanies the creative introduction of a task. During the years of 2018 \& 2019, more than 500 individuals of three members teams were registered in the competition.

The mathematical problem solving and tool use, as well as, creative presentation, rely on multiple skills [2]. The first one is aimed at outstanding navigation in the world of information, the conscious application of information, whilst the second may be specified with specific skills of social advocacy. Accordingly, it is worth checking, what results have the participating teams achieved in math-specific, and 
what in presentation-specific tasks. Based on the results, we are looking for the answer on the question, in what extent does mathematical knowledge is accompanied by creative presentation, task introduction, and based on the results of them, what consequences may be stated, what features may be demonstrated primarily regarding mathematical knowledge and tasks requiring creative introduction and presentation.

The application of mathability inspires the students to contribute with cognitive sciences by assimilating new information, building new knowledge, develop problem-solving abilities and experience, using modern ICT devices [3]. In this way, the mathability, as a combination of artificial and natural cognitive capabilities, supports the education process to co-evolves with infocommunication devices [4]-[9]. The perspectives of mathability inspired the main goals and methodology of the MaTech national competition.

In this article, the name MaTech1 refers to the competition in the school year 2017/2018, while MaTech2 refers to the competition in the school year $2018 / 2019$.

\subsection{MaTech - The Extraordinary Math Competition}

The MaTech competition consists of three rounds; the evaluation of each round is made separately. The first and second round is conducted online, while the final in real-time. Teams of 3 members from the $10^{\text {th }}$ and the $11^{\text {th }}$ class of secondary schools may apply to the competition. The territorial distribution of teams registered to the competition is shown in Figure 1 (settlements delegating less than five teams are not indicated).

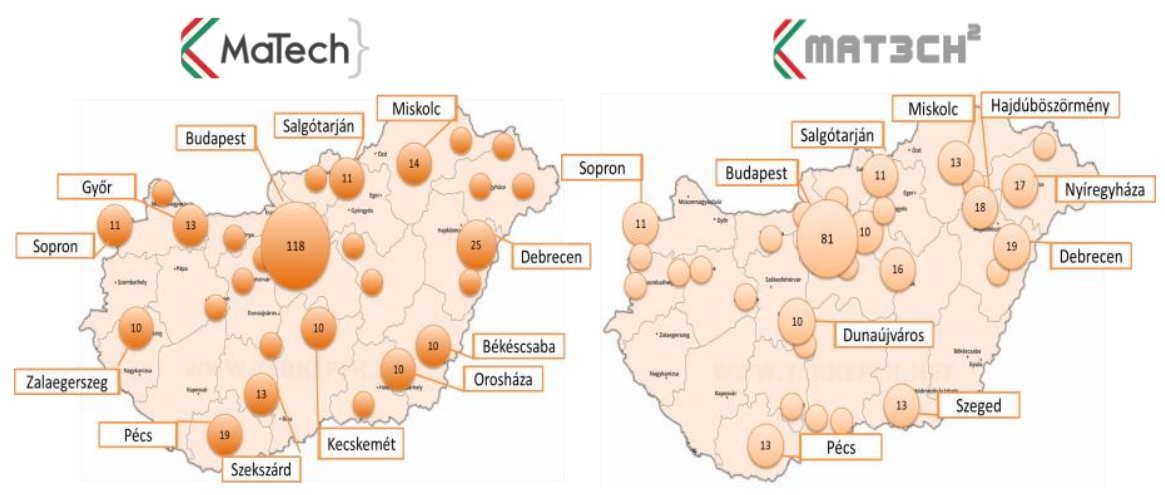

Figure 1

Territorial distribution of teams registered to the MaTech1 \& MaTech2 competitions 
The competition, beyond mathematical knowledge, focuses on creativity, digital tool use, problem-solving thinking and cooperation. The competition's individual nature is that it allows, moreover, requires, the use of smart tools, which is an absolute basic issue for today's secondary school students, meaning, that it has become an integral part, nowadays. For the successful participation in the competition, basic mathematical knowledge is obviously required, but the focus is on the improvement of thinking, experience-based learning and cooperation.

\subsection{Focus on Digital Tool Use}

The majority of the tasks of the MaTech competition, may be quickly and efficiently solved using digital tools; therefore, digital tool use is not prohibited at the competition, moreover, required. The use of digital tools is an opportunity, moreover, challenge for the team consisting of secondary school teachers, preparing the tasks. Among the tasks, the aim was the application of contents, features available online (image search, expressions, song parts, special contents), geographical searches had to be performed (GPS coordinates, Google Earth), reading of digital contents ( $\mathrm{QR}$ code), even mathematical applications available online had to be used (e.g. Wolfram Alpha, GeoGebra), moreover, their application was necessary for effective and quick problem solving. In the final phase, two notebooks and one tablet were available for the teams to solve the tasks.

\subsection{Creative Task Introduction, Presentation at the Final and in the Preliminary Tasks}

The MaTech competition, in addition to the creative nature of the mathematical tasks, provides such challenges against the competing teams, where social competences, presentation skills, creative task introduction and presentation manifest themselves following each other. These creative tasks provide the opportunity to present certain factors of social advocacy in real life, and to benefit from both individual and team skills. In the preliminary task of round 2, and certain tasks of the final, those activities are highlighted, where it is not mathematical problem solving that plays the major role. The solution of this preliminary task of round 2 had not been mandatory yet but had been worth extra point. In the final, however, these tasks were also highlighted and were worth almost $40 \%$ in the total evaluation.

The creative task of MaTech 1's round 2, to be prepared in advance, was the design of the MaTech logo, as well as the preparation of a one-minute mini-film, where the teams had to demonstrate the solution of a geometric task, as creative as possible. Two ready MaTech logos are shown in Figure 2. 


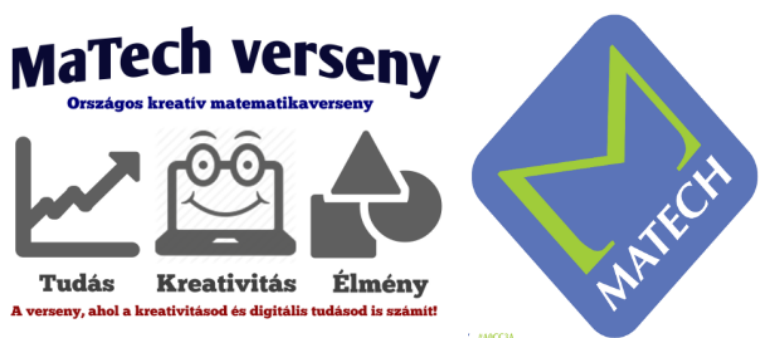

Figure 2

MaTech logo, as a preliminary task

The creative tasks of the MaTech1 Final were the preparation and demonstration of an infographic, and the introduction of the future of math education. In the Infographic task, the teams had to introduce themselves, their class, school and its environment live; however, all of these, through numbers, commented by quantities, data and correlations. In the task, it was up to the teams' imagination and creativity, how do they demonstrate it was using as innovative, creative, funny 'stats' and creative graphic elements as possible. A smart table was also available to illustrate the infographic to the teams.

One of the creative tasks of the MaTech2 Final, was again, the introduction, using an infographics, although, in the other creative task, the teams had to demonstrate their favorite math item not using a traditional presentation, but in some kind of genre (e.g. song, track, dance, epos, stand up, dispute, drama, poet letter, remonstrance). A presentation presented at the MaTech2 Final is shown in Figure 3 (on-site webcam streaming).

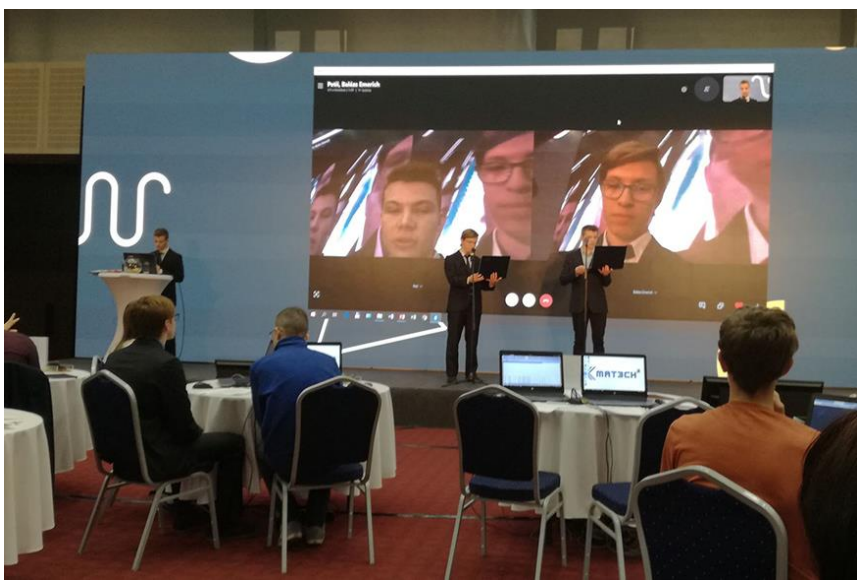

Figure 3

MaTech2 final creative task presentation 


\section{Creative Problem-Solving in Mathematics}

Creativity is a key complex cognitive process examined by cognitive sciences [10]. Cognitive sciences examine creativity by evaluating our brain's cognitive responses on external stimuli, processing the collected information [11], also analyzing the role of memory [12, 13] and attention [14].

Creativity involves innate behavior and learned behavior. Creativity may be represented within particular levels. The Four C Model developed by Beghetto \& Kaufmann [15] presents the potential levels of creativity within stages in life. 4 levels of creativity are identified:

- $\quad$ Big-C eminent creativity (like Picasso)

- $\quad$ Pro-C professional creativity

- $\quad$ Little-c everyday creativity

- Mini-c creativity involving learning

Creativity allows establishing a relationship between independent elements, to identify critical problems, respond on open questions on new ideas arising from curiosity. Creativity is represented in mathematics primarily in identifying new problems, working out of methods and tools of their solution, as well as the exploration of innovative methods serving as the resolution of unusual problems [16]. One method to establish original thinking situations is the presentation of open questions to the students, which requires a creative way of thinking and enables more than one answer [17].

Guilford [18] described creativity as problem-solving and concluded that the creative process has four stages:

- Recognition that a problem exists

- Production of a variety of relevant ideas

- Evaluation of the various possibilities

- Drawing of appropriate conclusions and solutions

Creativity and mathematical problem-solving correlate with each other, flexible thinking, which is one of the components of creativity, is one of the essential abilities in mathematical problem-solving. Based on Bishop's [19] experiences, two very different ways of thinking are required to solve mathematical problems: creative, intuitive, and analytic, logical way of thinking. According to Wachsmuth [20], problem-solving requires 'logical' and 'relaxation' mode in thinking.

For children, learning math is very important both regarding their later math studies and their general learning results in fields such as physics, science and technology [21], [22]. In several countries, creative mathematical problem-solving 
has not been integrated into the methodology of math education, but trained separately [23], [24]. Problem-solving is closely related to creativity in math too, primarily in those tasks, where a new solution had to be found on the new and the old problems [25]. So, in regards to mathematical knowledge, the revelation of new mathematical methods or ideas shall be highlighted, where a child's problem interpretation, illustration, creativity and reflection is in focus. Creativity develops, through the revelation of mathematical problems, both the development of problem-solving and a meaningful, logical way of thinking [26].

Technological development requires the application of mathematical knowledge and creative mathematical way of thinking in several fields. The report of the 2020 Science Group clearly highlights the available hardware and software capacity, which supports the solution of the world's complex problems, such as the planet's global warming or the spread of epidemics, although this might be a limiting factor in modelling such problems, where mathematics plays a vital role [27].

On the other hand, the everyday use of digital devices is usual among the young generation, that affects both the education system and the entire society. As a consequence of technological development, machines replace humans' role in more and more areas. Digital devices, however, become the determining tool of modern scientists, engineers and mathematicians, if they can properly use them. However, in math education, development of creative mathematical problemsolving, the credible use of digital tools has not been managed to (completely) integrate, in the fields of computerized algebra, modelling, simulation, statistics, data collection and 3D geometric [28].

As we can see above, by technological development, the spread of digital tools, the establishment of digital society, the ever-increasing scope of activities performed by the algorithms of machines, the relevance of creative mathematical problem-solving is becoming higher and higher. The mathability is also based on these findings and supports the cognitive processes to develop creative thinking and problem-solving abilities.

\section{Research}

The evaluation aimed to examine how a successful creative presentation accompanies mathematical knowledge. From the aspect of the evaluation, the sample consists of $10^{\text {th }}$ and $11^{\text {th }}$ class teams participating in the MaTech competition, which, due to the nationwide participation in regards to Hungary. The analyses presented in the research refer to teams participating in the competition. The evaluation is based on the performance analysis of teams entered to round 2 and the final, since round 1 relies only on tasks based on mathematical 
problem-solving, digital device use; thus the results achieved there are relevant only for either skill.

During the evaluation, among teams participating in Round 2, the results of those teams were evaluated, of which, had worked out the preliminary creative task too. All the 12 teams participated in the Final tested themselves in both task types; thus, the results of the Final's 12 teams were evaluated. During the evaluation, depending on the achieved number of points, each team was divided into four groups, regarding both tasks requiring primarily mathematical knowledge and creative presentation. These groups are: $0-25 \%, 25-50 \%, 50-75 \%$ and $75-100 \%$, respectively, depending on the result. The evaluation of the teams' results was made using prevalence analysis and statistical methods.

\section{Results and Conclusions}

Teams also solving the preliminary tasks of MaTech1 competition's Round 2, their classification upon their results achieved in Round 2 in the mathematical tasks and the preliminary creative tasks are shown in Figure 4. The summary of results achieved in the mathematical tasks and preliminary creative tasks is shown in Figure 5.
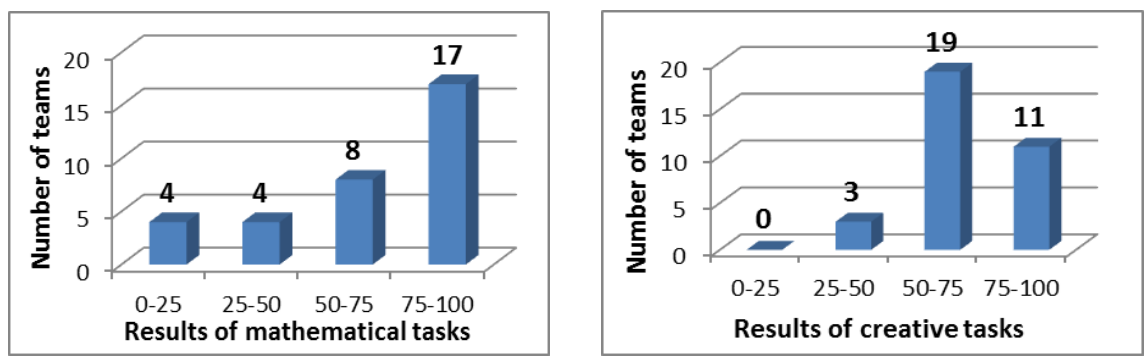

Figure 4

Number of teams participated to MaTech1, Round 2 according to their results achieved (horizontal: $0-25 \%, 25-50 \%, 50-75 \%$ and $75-100 \%$ depending on the results of Round 2) 

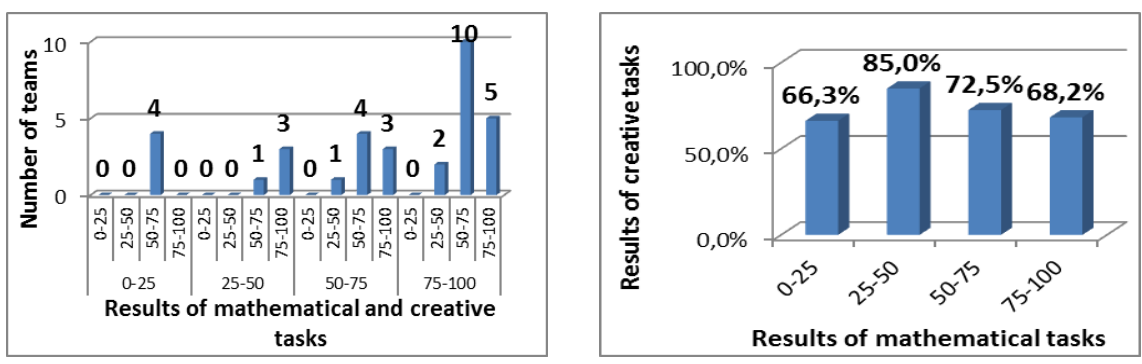

Figure 5

Comparison of results achieved in mathematical and creative tasks by teams participated to MaTech1,

\section{Round 2}

(horizontal: $0-25 \%, 25-50 \%, 50-75 \%$ and $75-100 \%$ depending on the mathematical results of Round 2 and its distribution according to the results of the creative tasks)

It is clearly demonstrated by Matech1, Round 2, that the creative preliminary task was mostly made by teams achieving higher points at mathematical tasks. During the evaluation of creative tasks, the tasks of most teams have reached 50-75\%. The comparison of mathematical and creative tasks shows that irrespective of the result achieved at the mathematical tasks, the average evaluation of the creative tasks were almost the same, in the range between $66-85 \%$, and was the highest at teams achieving lower, $25-50 \%$ results at mathematical tasks.

Similar results of MaTech2, Round 2 are summarized in Figures 6 and 7.
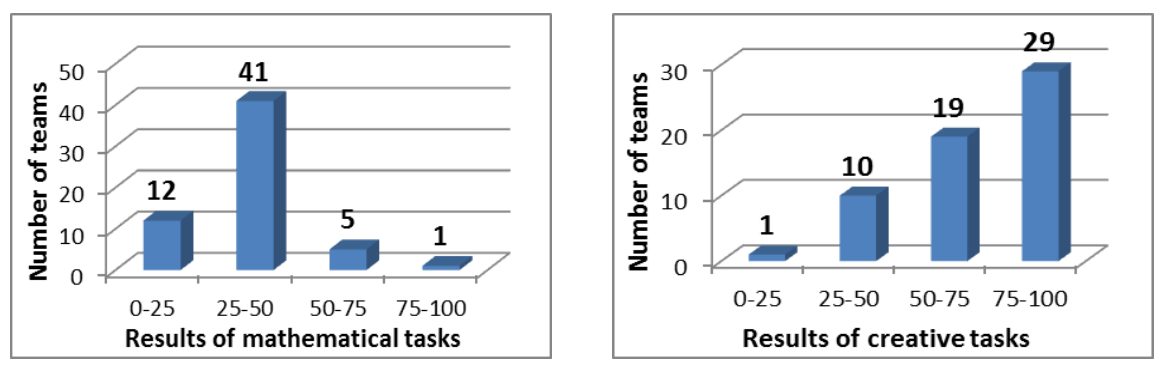

Figure 6

Number of teams participated to MaTech2 Round 2 according to their results achieved (horizontal: $0-25 \%, 25-50 \%, 50-75 \%$ and $75-100 \%$ depending on the results of Round 2) 

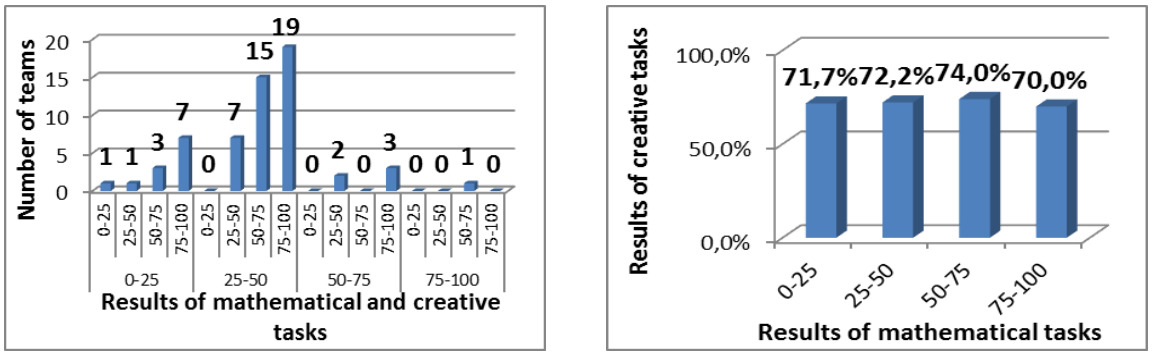

Figure 7

Comparison of results achieved in mathematical and creative tasks by teams participated to MaTech2,

\section{Round 2}

(horizontal: $0-25 \%, 25-50 \%, 50-75 \%$ and $75-100 \%$ depending on the mathematical results of Round 2 and its distribution according to the results of the creative tasks)

It was clearly shown by Matech2 Round 2, that points achieved at mathematical tasks were lower; most teams were categorized into the 25-50\% range. However, during the evaluation of creative tasks, the results of most teams were evaluated to $75-100 \%$, indicating that teams are more and more prepared in this field too.

The comparison of mathematical and creative tasks indicates that irrespective of the results achieved at mathematical tasks, the average evaluation of the creative tasks were almost the same, within the $70-74 \%$ range, so practically there were no outstanding results in this grouping.

The comparison of the results of Round 2 of both MaTech1 and MaTech2 indicates that the mathematical tasks of MaTech2 proved to be more difficult for the teams, although they had more success in creative tasks. In both years, it is clear that results achieved at mathematical and creative tasks do not correlate, meaning that the evaluation of creative tasks is irrespective of the results achieved at mathematical tasks.

In case of the MaTech finals, the evaluation drafted above may also be performed. In the finals of both MaTech1 and MaTech2, the most successful 12 teams were participating. The evaluation of MaTech1

Final with similar aspects as above is summarized in Figure 8 and 9. 

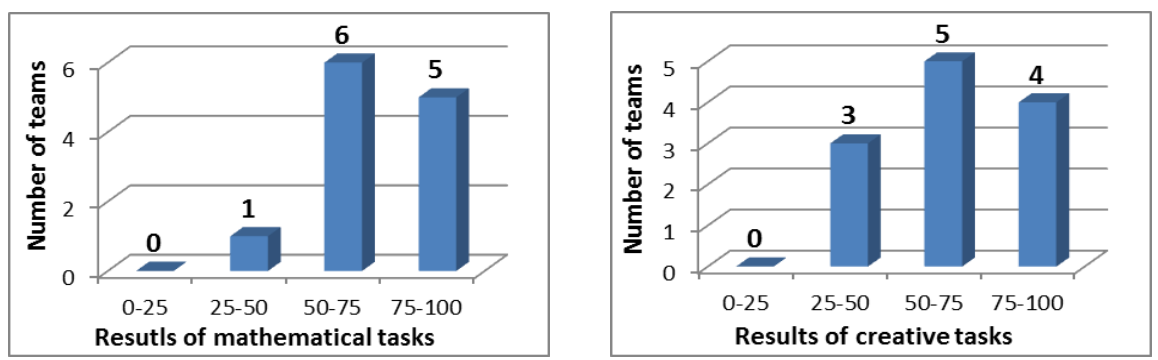

Figure 8

Number of teams participated to MaTech1 Final according to their results achieved (horizontal: $0-25 \%, 25-50 \%, 50-75 \%$ and $75-100 \%$ depending on the results of Final)
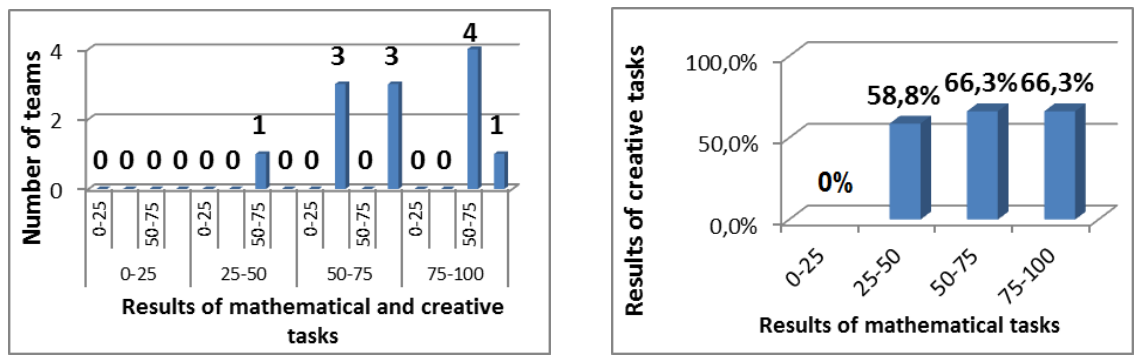

Figure 9

Comparison of results achieved in mathematical and creative tasks by teams participated to MaTech1 Final

(horizontal: $0-25 \%, 25-50 \%, 50-75 \%$ and $75-100 \%$ depending on the mathematical results of Final and its distribution according to the results of the creative tasks)

In the case of MaTech2 Final, the results of the evaluation are shown in Figure 10 and 11 .
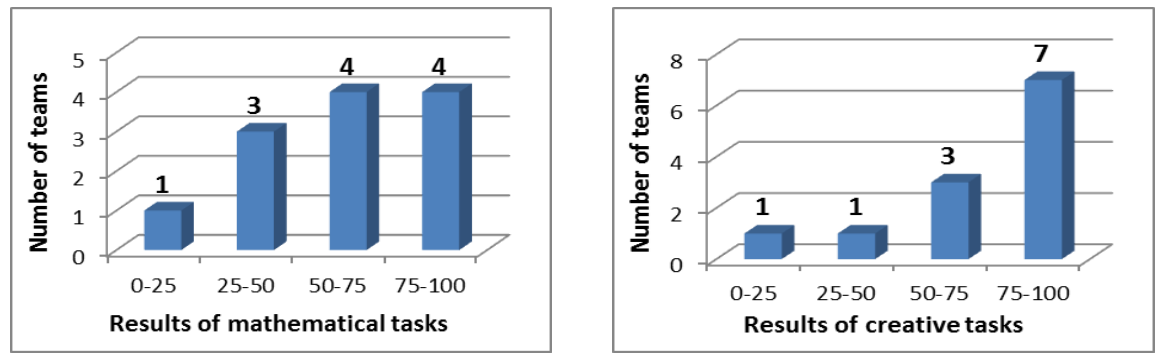

Figure 10

Number of teams participated to MaTech2 Final according to their results achieved (horizontal: $0-25 \%, 25-50 \%, 50-75 \%$ and $75-100 \%$ depending on the results of Final) 

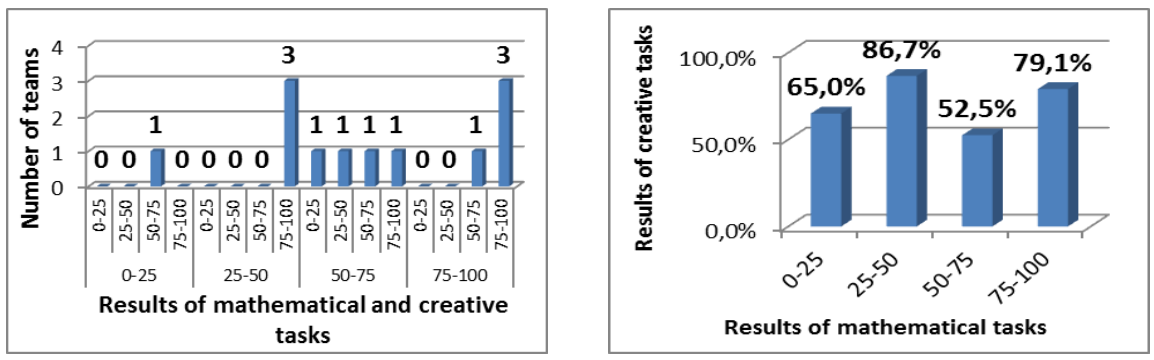

Figure 11

Comparison of results achieved in mathematical and creative tasks by teams participated to MaTech2 Final

(horizontal: $0-25 \%, 25-50 \%, 50-75 \%$ and $75-100 \%$ depending on the mathematical results of Final and its distribution according to the results of the creative tasks)

The comparison of MaTech1 and MaTech2 finals indicate that since the solutions of the mathematical tasks of MaTech2 were slightly less successful for the teams, an improvement is detected at creative tasks, 7 teams achieved results varying between 75 and $100 \%$. Similarly, to the results of Round 2, the Final also demonstrated that results achieved on mathematical and creative tasks do not correlate in both years; in case of MaTech1 Final, the results achieved at creative tasks appear virtually irrespective of the results achieved at mathematical tasks that vary between $59 \%$ and $66 \%$. In case of the MaTech2 Final, primarily compared to the results achieved at mathematical tasks, the evaluation of creative tasks varied between $52 \%$ and $87 \%$; however, there is no correlation in the results, meaning that the evaluation of creative tasks is irrespective of the results achieved at mathematical tasks.

It is clear that the success of teams in tasks based on primarily mathematical knowledge does not correlate with tasks requiring a creative presentation, they show no correlation on the level of the individual skills.

\section{Summary}

The consequences of the evaluation of the competition results, indicates that, in the MaTech competition, results achieved at tasks requiring primarily mathematical knowledge, do not correlate with the success shown in tasks requiring a creative presentation. This finding indicates that in addition to lexical knowledge, the improvement of skills requiring creative presentation should also be taken into consideration. However, it is quite promising, that compared to MaTech1, there were better results within the solutions of the creative tasks of MaTech2 both regarding Round 2 and the Final. Skills requiring creative presentation have outstanding relevance in social advocacy; therefore, it is 
important to emphasize these competencies in the course of the education of the generations grounding within our future information based society. In the MaTech competition, these competencies also play a significant role in providing a unique feature to the competition, by focusing on digital competences. The ICT and a special topic, in this field, Cognitive Info-communication has the ability to emphasize the competencies of the new generation, through the power of gamification, cooperation, project based learning [29]-[32], cognitive ICT [33][37] or virtual spaces for improving attention and interest [38]-[42] and the extension of memory [43].

\section{Acknowledgement}

This research was supported by EFOP-3.6.1-16-2016-00003 grants, Establishment long-term R \& D \& I process at the University of Dunaujvaros.

\section{References}

[1] MaTech webpage, [Online]. Available: http://matechversenyek.hu/ [Accessed: Sept. 7, 2019]

[2] Grégoire J.: Understanding Creativity in Mathematics for Improving Mathematical Education, Journal of Cognitive Education and Psychology, Vol. 15, No. 1, 2016, 24-36

[3] Katarzyna Chmielewska, Attila Gilányi: Educational Context of Mathability, Acta Polytechnica Hungarica, Vol. 15, No. 5, 2018, pp. 223 237

[4] Peter Baranyi, Attila Gilányi: Mathability: Emulating and enhancing human mathematical capabilities, Proceedings of the $4^{\text {th }}$ International Conference on Cognitive Infocommunications (CogInfoCom), Budapest, 2013, pp. $555-558$

[5] Katarzyna Chmielewska, Attila Gilányi: Mathability and computer aided mathematical education, Proceedings of the $6^{\text {th }}$ IEEE International Conference on Cognitive Infocommunications (CogInfoCom), Gyor, 2015, pp. 473-477

[6] Katarzyna Chmielewska, Attila Gilányi, Agnieszka Łukasiewicz: Mathability and mathematical cognition, Proceedings of the $7^{\text {th }}$ IEEE International Conference on Cognitive Infocommunications (CogInfoCom), Wroclaw, 2016, pp. 245-250

[7] Katarzyna Chmielewska, Attila Gilányi: Computer Assisted Activating Methods in Education, Proceedings of the $10^{\text {th }}$ IEEE International Conference on Cognitive Infocommunications (CogInfoCom), Naples, 2019, pp. 241-246

[8] Attila Gilányi: Charakterisierung von monomialen Funktionen und Lösung von Funktionalgleichungen mit Computern, $\mathrm{PhD}$ Thesis, University of Karlsruhe, 1995 
[9] Attila Gilányi: Solving linear functional equations with computer, Math. Pannon., 9:57-70, 1998

[10] Peter H. Lindsay, Donald A. Norman: Human Information Processing, New York, Academic Press, 1977

[11] Folgieri Rafaella, et al: Art in the neuroscience ERA: how the brain understands and creates art, Electronic Imaging \& the Visual Arts, Vol. 111, 2016, pp. 90-95

[12] Folgieri Raffaella, et al.: Brain, technology and creativity. BrainArt: A BCI-based entertainment tool to enact creativity and create drawing from cerebral rhythms. In: Digital Da Vinci. Springer, New York, NY, 2014, pp. 65-97

[13] Costescu Cristina, Rosan Adrian, Nagy Brigitta, Heldal Ilona, Helgesen Carsten, Kővári Attila, Katona József, Thill Serge, Demeter Róbert, Efrem Igor: Assessing Visual Attention in Children Using GP3 Eye Tracker, Proceedings of the $10^{\text {th }}$ IEEE International Conference on Cognitive Infocommunications, 2019, pp. 343-348

[14] Gogh, E., Kovari, A.: Metacognition and Lifelong Learning: A survey of secondary school students, $9^{\text {th }}$ IEEE International Conference on Cognitive Infocommunications, 2018, pp. 271-276

[15] Kaufman James C.: Beghetto, Ronald A: Beyond big and little: The four c model of creativity, Review of general psychology, 2009, Vol. 13, No. 1, 2009, pp. 1-12

[16] Aini, Afifah Nur, et al.: Student's Mathematics Creative Thinking Skills in Terms of Logical Mathematical Intelligence, International Journal of Scientific Research and Management, Vol. 5, No. 9, 2017, pp. 6930-6934

[17] Wiliam Dylan: Assessing authentic tasks: alternatives to mark-schemes, Nordic Studies in Mathematics Education, Vol. 2, No. 1, 1994, pp. 48-68

[18] Joy Paul Guilford: Creativity. American Psychologist, Vol. 5, No. 9, 1950, pp. $444-454$

[19] A Bishop: Visuelle Mathematik, Fragen des Geometrieunterrichts, 1981, pp. $166-184$

[20] Ipke Wachsmuth: Two modes of thinking - also relevant for the learning of mathematics?, For the Learning of Mathematics, Vol. 2, No. 2, 1981, pp. $38-45$

[21] Cross Christopher T., Woods Taniesha A., Schweingruber Heidi E.: Mathematics learning in early childhood: Paths toward excellence and equity, National Academies Press, 2009

[22] Duncan Greg J., et al.: School readiness and later achievement, Developmental psychology, 2007, Vol. 43, No. 6, pp. 1428-1446 
[23] Cai Jinfa: Commentary on problem-solving heuristics, affect, and discrete mathematics: A representational discussion, Theories of mathematics education: Seeking New Frontier, Springer, Berlin, Heidelberg, 2010, pp. 251-258

[24] English Lyn, Sriraman Bharath: Problem-solving for the $21^{\text {st }}$ Century, Theories of mathematics education, Springer, Berlin, Heidelberg, 2010, pp. 263-290

[25] Craft Anna: Creativity and early years education: A lifewide foundation. A\&C Black, 2002

[26] Lesh Richard: Problem solving and modelling. Second handbook of research on teaching and learning, Vol. 2, 2007, pp. 763-804

[27] The 2020 Science Group, Towards 2020 Science. 2006, Microsoft Research: Cambridge, UK

[28] Hoyles Celia, et al.: Improving mathematics at work: The need for technomathematical literacies, Routledge, 2010

[29] György Molnár: The Impact of Modern ICT-based Teaching and Learning Methods in Social Media and Networked Environment, Proceedings of the $11^{\text {th }}$ International Scientific Conference on Distance Learning in Applied Informatics, Nitra, 2016, pp. 341-350

[30] Ildiko Horvath: Innovative engineering education in the cooperative VR environment, Proceedings of the $7^{\text {th }}$ IEEE Conference on Cognitive Infocommunications (CogInfoCom), Wrocław, 2016, pp. 359-364

[31] Robert Pinter, Sanja Maravic Cisar: Measuring Team Member Performance in Project Based Learning, Journal of Applied Technical and Educational Sciences, Vol. 8, No. 4, 2018, pp. 22-34

[32] Elod Gogh and Attila Kovari: Experiences of Self-regulated Learning in a Vocational Secondary School, Journal of Applied Technical and Educational Sciences, Vol. 9, No. 2, 2019, pp. 72-86

[33] Ildikó Horváth: Evolution of teaching roles and tasks in VR/AR-based education, Proceedings of the $9^{\text {th }}$ IEEE International Conference on Cognitive Infocommunications (CogInfoCom), Budapest, 2018, pp. 355360

[34] Gergely Sziladi et al.: The analysis of hand gesture based cursor position control during solve an IT related task, $8^{\text {th }}$ IEEE International Conference on Cognitive Infocommunications, 2017, pp. 413-418

[35] Attila Kovari: CogInfoCom Supported Education: A review of CogInfoCom based conference papers, Proceedings of the $9^{\text {th }}$ IEEE International Conference on Cognitive Infocommunications (CogInfoCom), 2018, pp. 233-236 
[36] Cristina Costescu and Adrian Rosan: Development an assessment protocol to identify the characteristics of ASD using eye-tracking for special education purpose, Journal of Applied Technical and Educational Sciences, Vol. 9, No. 4, 2019, pp. 70-87

[37] Peter Baranyi, Adam Csapo, Gyula Sallai, Cognitive Infocommunications (CogInfoCom), Springer International Publishing Switzerland, 2015, p. 219

[38] Laszlo Bognar, Eva Fancsikne, Peter Horvath, Antal Joos, Balint Nagy, Gyorgyi Strauber: Improved learning environment for calculus courses, Journal of Applied Technical and Educational Sciences, Vol. 8, No. 4, 2018, pp. 35-43

[39] Tibor Guzsvinecz, Csaba Kovacs, Dominich Reich, Veronika Szucs, Cecilia Sik-Lanyi: Developing a virtual reality application for the improvement of depth perception, $9^{\text {th }}$ IEEE International Conference on Cognitive Infocommunications, 2018, pp. 17-22

[40] György Molnár: The role of electronic and virtual learning support systems in the learning process, Proceedings of the 8th International Symposium on Applied Computational Intelligence and Informatics, Timisoara, 2013, pp. $51-54$

[41] Cecilia Sik-Lányi, Veronika Szücs, Janet Stark: Virtual reality environments development for aphasic clients, International Journal of Stroke, 2014, pp. 241-250

[42] Ilona Heldal, Carsten Helgesen: The Digital HealthLab: Supporting Interdisciplinary Projects in Engineering and in Health Education, Journal of Applied Technical and Educational Sciences, Vol. 8, No. 4, 2018, pp. 421

[43] Adam Csapo, Ildiko Horvath, Peter Galambos and Peter Baranyi: VR as a Medium of Communication: from Memory Palaces to Comprehensive Memory Management, Proceedings of the $9^{\text {th }}$ IEEE International Conference on Cognitive Infocommunications (CogInfoCom), Budapest, 2018, pp. 389-394 